ARCHIVO ESPAÑOL DE ARTE, LXXXII, 328

OCTUBRE-DICIEMBRE 2009, pp. 393-424

ISSN: 0004-0428

\title{
VARIA
}

\section{EL PSEUDO-HIEPES ES BERNARDO POLO}

\begin{abstract}
Hace unos quince años, el autor propuso el apodo Pseudo-Hiepes para identificar al pintor anónimo a quien algunos entendidos italianos habían bautizado como Maestro del Frutero lombardo. En aquel entonces, argumentó que debía tratarse de un artista aragonés, de la segunda mitad de siglo. Por fin ha aparecido una obra firmada que se presenta aquí. Efectivamente, el artista era zaragozano y su nombre es Bernardo Polo.

Palabras clave: Pintura española; Siglo XVII; Bodegón; Maestro del Frutero Lombardo; Pseudo-Hiepes.

Nearly fifteen years ago, the author proposed the name Pseudo-Hiepes to refer to a then anonymous painter whom certain Italian art historians had called the Master of the Lombard Fruit Bowl. At the time, he argued for an Aragonese origin in the later part of the century. A signed work has finally been discovered and is published here. The artist was indeed from Zaragoza, and his name is Bernardo Polo.
\end{abstract}

Key words: $17^{\text {th }}$ century; Still-life painting; Master of the Lombard Fruit Bowl; Pseudo-Hiepes.

En 1995, junto con Peter Cherry, propuse el apodo Pseudo-Hiepes para identificar a un pintor aun anónimo pero cuya personalidad de bodegonista prolífico se hacía cada vez más patente, debido a la frecuente aparición de obras suyas en el mercado ${ }^{1}$. En aquel entonces, y de nuevo en $1997^{2}$, puse en entredicho la sugerencia de los entendidos italianos, basada en una obra que se encontraba en la colección Lorenzelli de Bergamo (fig. 1), de que se trataba de un artista italiano de principios del siglo XVII, que debía de conocerse como Maestro del Frutero Lombardo ${ }^{3}$. Abogué a favor de un origen español, más bien aragonés, y traté de definir su estilo a través de una cuarentena de naturalezas muertas de su mano que me eran conocidas, la mayoría ubicadas en España. Parecía inevitable que la verdadera identidad de este maestro fuera a ser un misterio hasta que apareciera un cuadro suyo firmado. Por suerte, mientras han ido saliendo a la luz cada vez más ejemplares, esto ha ocurrido. Al fin podemos desvelar aquí que el Pseudo-Hiepes era un pintor zaragozano cuyo renombre como bodegonista en el último tercio del siglo XVII llegó hasta la misma Villa y Corte de Madrid, según los testimonios de Palomino y Ceán Bermúdez. Su nombre es Bernardo Polo ${ }^{4}$.

\footnotetext{
1 Jordan, William B. y Cherry, Peter: Spanish Still Life from Velázquez to Goya, cat. exp., Londres (National Gallery, 1995, pp. 124-128.

2 Jordan, William B.: An Eye on Nature. Spanish Still-Life Paintings from Sánchez Cotán to Goya, cat. exp., Londres (Matthiesen Gallery), 1997, pp. 116-126.

3 Ver SpIKE, John T.: Italian Still Life Painting from Three Centuries, cat. exp., Nueva York (National Academy of Design), 1983, p. 27; SALERno, Luigi: Still Life Painting in Italy: 1560-1805, Roma, 1984, p. 18; L. Salerno, Natura morta italiana (Sammlung Silvano Lodi), cat. exp., Münich (Alte Pinakothek), 1984-85, p. 35.

${ }^{4}$ Agradezco a James Macdonald y a Andrew Fletcher el haberme dado a conocer la pintura que da lugar a esta identificación.
} 


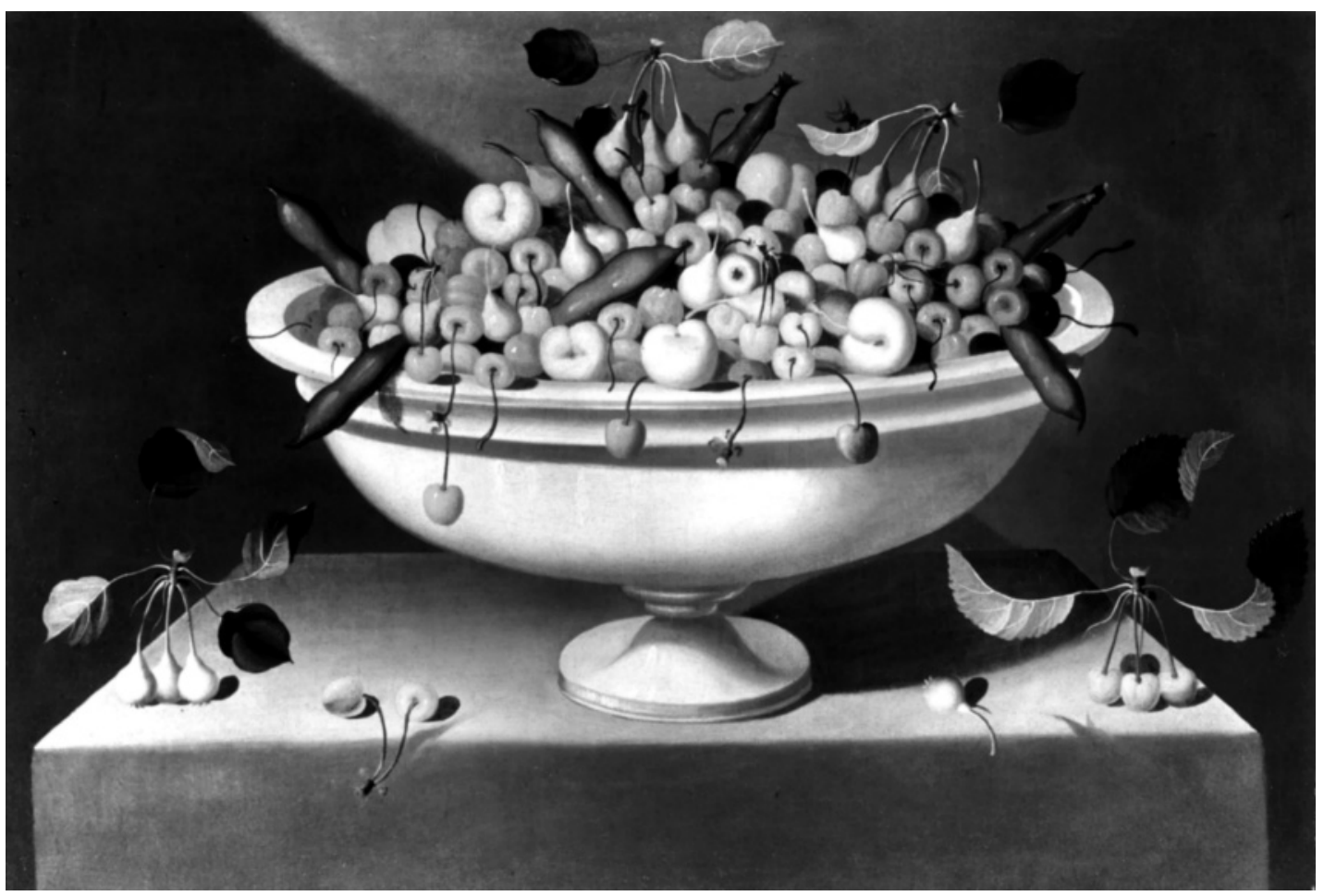

Fig. 1. Bernardo Polo, Frutero con cerezas, albaricoques, cermeñas y judías. Colección Lorenzelli, Bérgamo.

Tal y como reseñé en 1995, el artista encabezaba un taller que hacía uso de un reducido repertorio de modelos compositivos, con un sinfín de variaciones, pero con un reparto de objetos casi fijo. Por feliz casualidad, la recién aparecida obra firmada de Bernardo Polo, que resuelve el misterio de su personalidad, corresponde en lo compositivo al cuadro que dio lugar al malogrado apelativo "Maestro del Frutero Lombardo" (fig. 1). Aquel cuadro, que mide $49 \times 74 \mathrm{cms}$., representa una peana independiente de piedra, sobre la que descansa un frutero de loza blanca, algo genérico, que rebosa cerezas, albaricoques, cermeños y judías. Tal y como ocurre en la mayoría de sus obras, cae una fuerte luz desde la parte superior izquierda, que divide la composición en diagonal de forma dramática. Este golpe de efecto, que recuerda las obras de Caravaggio, es uno de los rasgos que llevó a los italianos a considerar suyo el pintor ${ }^{5}$. Sin embargo, junto con la preferencia por las composiciones simétricas y algo estáticas, la sombra más bien delata a un pintor algo arcaicista, activo en provincias a finales de siglo. Su manera de hacer es representar primero la peana y la exagerada sombra diagonal sobre un fondo de tierra ocre finamente velada, y luego retratar los objetos con sus sombras individuales por encima ${ }^{6}$. Así ocurre con la naturaleza muerta firmada por Bernardo Polo (fig. 2) aunque en este caso el lienzo haya sido recortado

5 Salerno (Münich, 1984-85) afirmó: "This is the kind of still life that Caravaggio must have painted when he first joined the workshop of Simone Peterzano".

${ }^{6}$ Este método de componer los cuadros lo implementó en España Sánchez Cotán, que acostumbraba pintar primero las "ventanas", como las llamaba él, y añadir a continuación los objetos que cuelgan y descansan dentro del espacio demarcado: ver: JoRDan, William B.: Spanish Still Life in the Golden Age: 1600-1650, cat. exp., Fort Worth (Kimbell Art Museum), 1985, p. 48. 


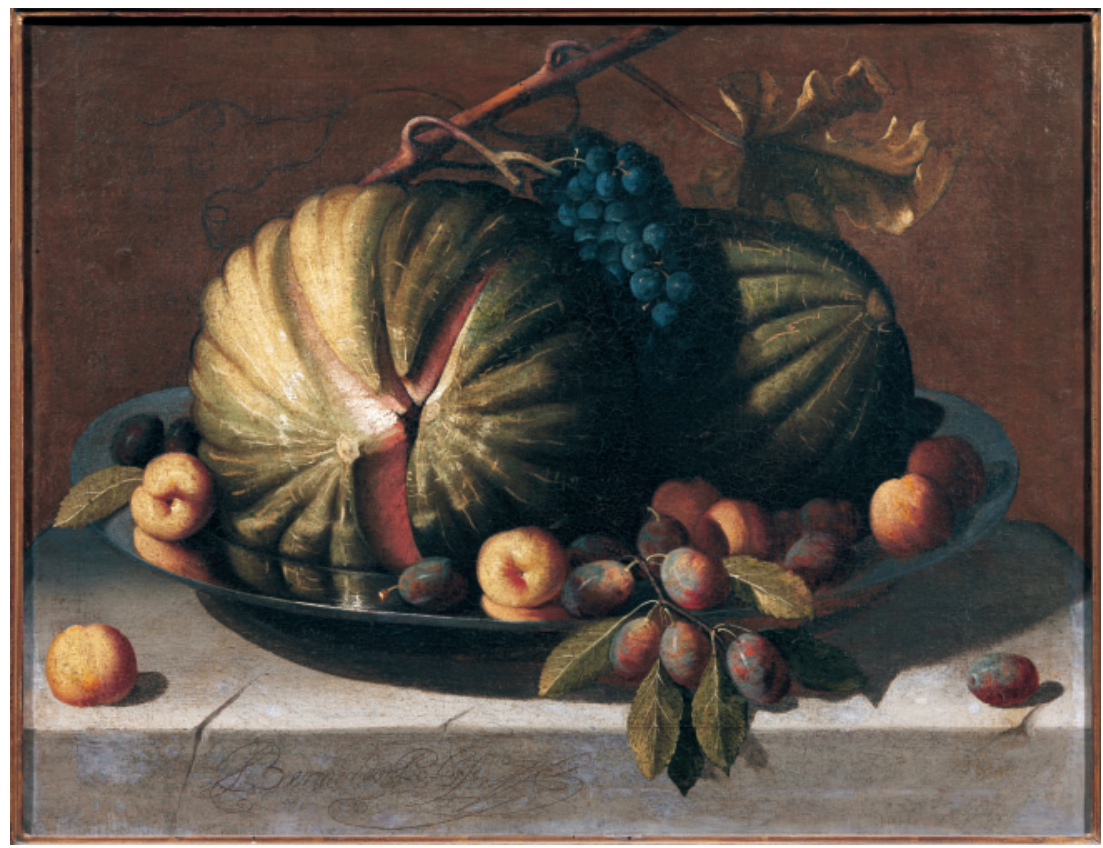

Fig. 2. Bernardo Polo, Salvilla con melones, uvas, albaricoques y ciruelas. Colección particular.

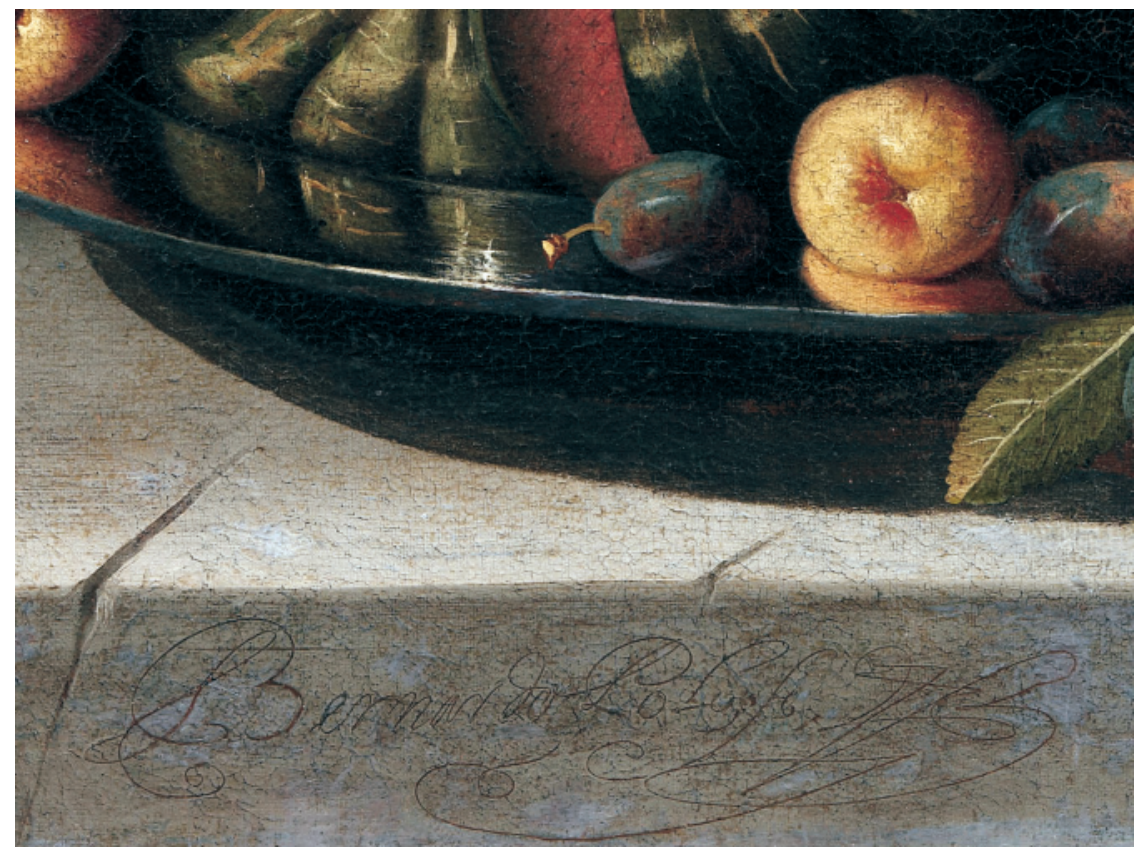

Fig. 3. Bernardo Polo, Salvilla con melones, uvas, albaricoques y ciruelas. Colección particular, detalle de la firma.

AEA, LXXXII, 328, OCTUBRE-DICIEMBRE 2009, 393-424, ISSN: 0004-0428 
en momento posterior (que altera el aspecto de peana aislada) y el fondo del cuadro haya sufrido una limpieza agresiva, lo cual dificulta la apreciación inmediata de la sombra ${ }^{7}$.

Un plato que sostiene dos melones y un racimo de uvas, al igual que albaricoques y ciruelas: tal es el arreglo que descansa sobre plinto de piedra gris en la naturaleza muerta recién aparecida de Bernardo Polo. Sabemos que es obra segura suya por la elegante rúbrica-Bernardo Polo, fe.- que aparece como ornamento inciso en el pigmento aun mojado del plinto (fig. 3). Este plinto se representa con un trampantojo de fisuras e imperfecciones por todo el frontal, al igual que se observa en el famoso Frutero con cerezas, albaricoques, cermeños y judías, dado de antaño al Maestro del Frutero Lombardo, pero, una vez más, estos detalles son menos evidentes en la actualidad, debido a la dura forración que ha sufrido el cuadro, y a una limpieza poco sensible. El lienzo nuevo no ha sido forrado con la misma severidad, pero ha sido maltratado de distinta forma. Lo más evidente es que ha sido reducido de tamaño, sobre todo a lo ancho, unos veinte centímetros (las dimensiones actuales son $43 \times 56 \mathrm{cms}$.). En gran parte, esto ha resultado en una disminuida perspectiva a los lados de la piedra, que debió ser importante en definir el espacio alrededor del frutero. Además, una mirada detenida de la obra desvela que la sombra diagonal que en su origen cruzaba en descenso la composición de izquierda a derecha, al igual que otras modulaciones en los fondos, han sido barridas, dejando uniforme el espacio de tierra ocre. De la sombra ya sólo quedan restos de veladuras oscuras en la zona superior a las uvas, y en algunos puntos localizados de los fondos, hacia el lado izquierdo ${ }^{8}$. De todas formas, si hacemos caso omiso a estas alteraciones posteriores, se ve que las dos composiciones bien pudieran funcionar como pareja.

Al igual que sucede con el arreglo de Frutero con cerezas, albaricoques, cermeños y judías, que fue repetido por Bernardo Polo en varias ocasiones, la presentación de Salvilla con melones, uvas, albaricoques y ciruelas, la obra firmada de reciente aparición, puede verse también en otras varias composiciones mayores. Dos de ellas, en especial, indican como debió ser la manera de laborar del taller. En Bodegón con jarrón de flores, frutero y enfriador de vino (fig. 4), de colección particular barcelonesa, todos los elementos se disponen sobre un plinto rectangular de piedra, la cornisa tallada con un motivo de hojas. Al centro de la composición, figura el mismo plato de melones, uvas, albaricoques y ciruelas. Pero esta vez a su izquierda vemos un florero, cuyo jarrón parece una interpretación algo esquemática de los elegantes vasos napolitanos de vidrio azul y monturas de cobre dorado, de motivos grotescos, que ya habían representado, quizás con más esmero, pintores anteriores como Van der Hamen. A la derecha vemos un enfriador de corcho, también algo genérico. Por encima de todo cuelga un racimo de uvas negras, realzado por un curioso detalle espacial: una esquina descolgada en segundo término, sin función arquitectónica evidente, ni relación alguna con el plinto. Este elemento extraño era sin duda del agrado de Bernardo Polo, ya que lo incluyó en varios cuadros suyos ${ }^{9}$. Entre ellos se encuentra una segunda versión del Bodegón con jarrón de flores, frutero y enfriador de vino (fig. 5) que yo vi hace unos años en una importante colección privada suiza. En esta encarnación de la misma composición, las flores del ramo son completamente distintas. Las uvas negras han sido remplazadas por unas blancas, y el acabado algo más duro, sobre todo de los melones y de las uvas, pudiera llevar a pensar en la intervención de otra mano. De hecho, entre los numerosos productos procedentes del taller de Bernardo Polo, la amplia variedad de calidades nos sugiere que debía de ser una empresa bastante aparatosa, contando con la intervención de varios pintores.

\footnotetext{
${ }^{7}$ La procedencia más reciente la desvela la etiqueta que figura al dorso, en la que se lee: "Sala Parés 1961/Bernardo Polo".

8 Agradezco a Rocío Dávila su examen de la pintura, y sus indicaciones en cuanto a la conservación.

9 Uno de ellos es Naturaleza muerta con frutero, alcachofas y florero, en paradero desconocido, en el que el motivo del "frutero lombardo" ocupa el centro de la composición: ver Jordan y Cherry 1995, p. 125, fig. 100.
} 


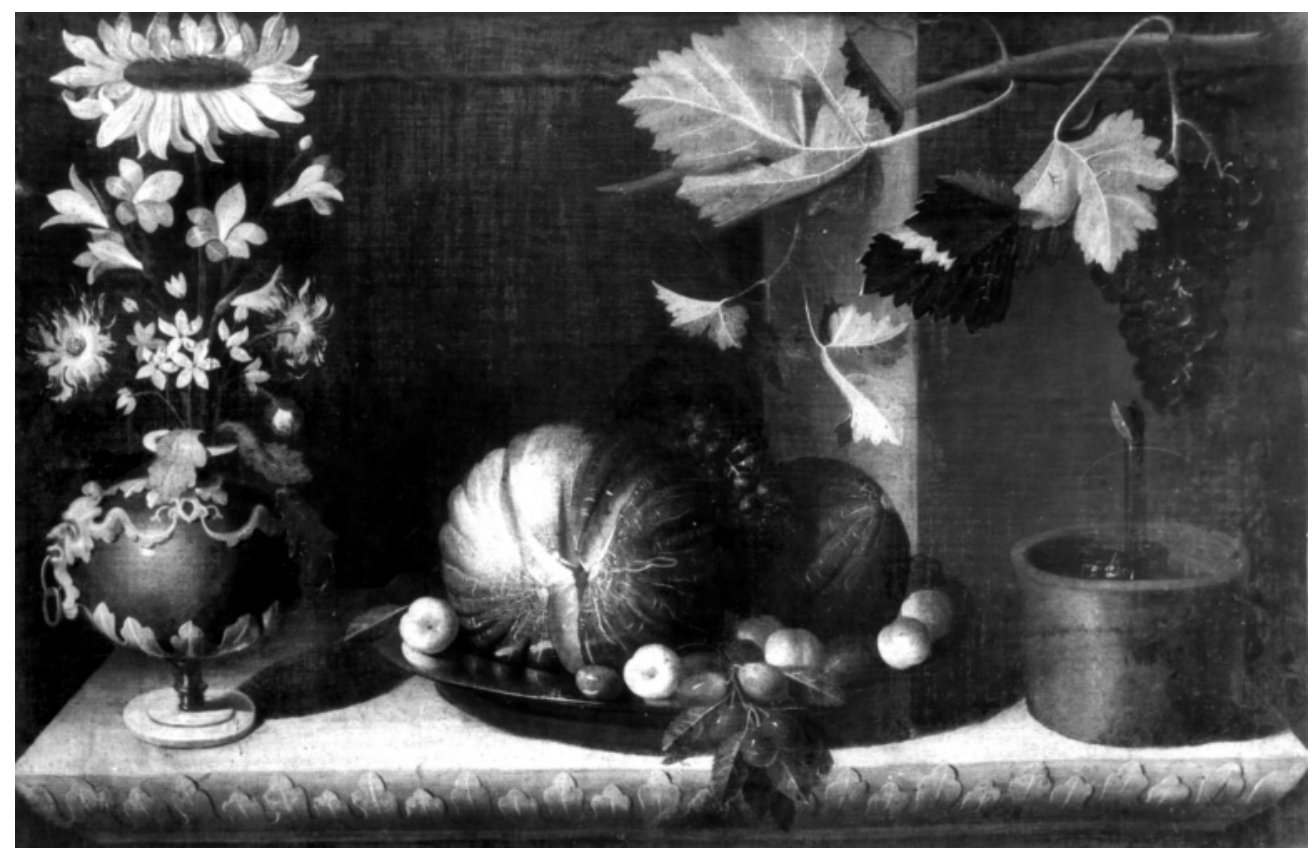

Fig. 4. Bernardo Polo, Bodegón con jarrón de flores, frutero y enfriador de vino. Colección particular, Barcelona.

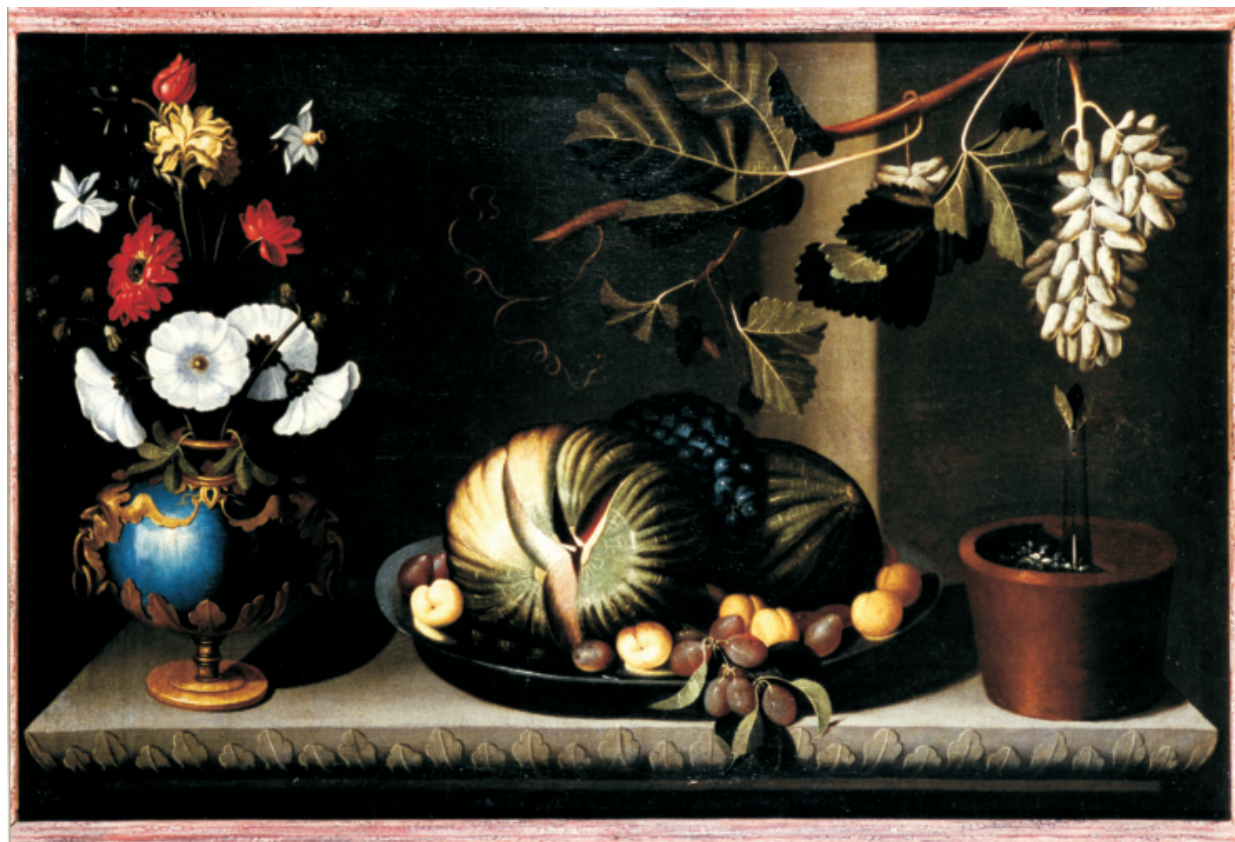

Fig. 5. Bernardo Polo, Bodegón con jarrón de flores, frutero y enfriador de vino. Antes colección particular, Suiza. 
Dicho esto, donde vemos a Bernardo Polo en su mejor momento es en un conjunto de seis lienzos que aun pertenecen a una distinguida colección madrileña, y de los cuales ya publiqué dos cuando propuse el apelativo "Pseudo-Hiepes"10. En la actualidad, disponemos de fotografías de sólo cinco de éstos, encontrándose el último en paradero remoto. Estos lienzos, que no presentan las debilidades que se encuentran en los productos de ayudantes del taller, se encuentran además en óptimo estado de conservación. En 1870, cuando se encontraban en manos de Don Manuel Salvador López, fueron catalogados por el eminente restaurador y entendido Vicente Poleró Toledo como obra de Tomás Hiepes ${ }^{11}$. Hace poco, con la limpieza reciente de los cuadros, surgió una posible explicación del error de Poleró, ya que en uno de ellos apareció, abajo y a la izquierda, una sencilla firma apócrifa: "hiepes". Esta firma de letra pequeña y cursiva no coincide a ninguna firma conocida de Hiepes, que solía firmar con grandes mayúsculas, y sin duda es una aportación decimonónica. Esto, junto con la correspondencia generalizada de las tipologías, hace comprensible la confusión del catalogador valenciano. En el entretanto, el apelativo "Pseudo-Hiepes" ha servido de comodín.

Es evidente el enorme atractivo decorativo de estas naturalezas muertas, y esta es sin duda la razón por la que se producían en conjuntos ${ }^{12}$. En este caso, la serie recogida por Poleró contiene muchos de los motivos predilectos de Bernardo Polo. Los lienzos son todos de dimensiones parecidas, $77 \times 115 \mathrm{cms}$. De ellos, cuatro (figs. 6, 7, 8, y el que falta aun por fotografiar) presentan unas composiciones más bien simétricas, dispuestas sobre plintos independientes de piedra, con sus decoraciones de hojas talladas, iguales a los de las figs. 4 y 5 , ya descritos. Los otros dos (figs. 9 y 10) sitúan los objetos encima de unos bufetes vestidos de un terciopelo rojo que lleva como remate un fleco sujeto con grandes clavos de latón. Estos dos tipos compositivos, junto con el de un solo elemento aislado, colocado sobre un sencillo plinto cúbico, como se ve en la obra firmada de Polo (fig. 2), constituyen los tres tipos de pintura que comprende la mayoría de su producción.

Al igual que ocurre con las obras de Hiepes, en las composiciones de Polo sobre unas bases de piedra, los elementos se ven siempre de frente, mientras los costados de la peana tallada se alejan de forma simétrica, y la luz cae siempre de izquierda a derecha. Aun así, las cuatro obras de esta tipología del conjunto madrileño pueden dividirse en dos parejas según su temática. En dos de estas -Alcachofa, codorniz y florero (fig. 6) y Panal, frutas y florero (fig. 7)- figuran como motivos centrales unos jarrones idénticos de vidrio que contienen arreglos complementarios de flores y ramos frutales ${ }^{13}$. En la otra pareja-Canastilla de fruta, chochas y peras (fig. 8) y Canastilla de fruta, codorniz y reclamo (de la que no existe imagen)- figuran al centro unas canastillas con frutas con ramos a los $\operatorname{lados}^{14}$. Ya que tres de las cuatro contienen caza menor, puede verse la temática compartida de la cacería y de la cosecha. Las dos que contienen flores son de colorido especialmente rico, y están ejecutadas con gran finura.

10 Jordan, W. B. y Cherry, P.: 1995, pp. 126-127, cat. no. 48 y fig. 101.

11 El propietario actual desciende del de 1870 y aún guarda el inventario manuscrito. Para el papel que jugó Poleró en la creación del moderno Museo de Prado, ver Museo del Prado, Inventario General de Pinturas II. El Museo de la Trinidad, Madrid, 1991, pp. 13-14.

12 Se conocen varias series de cinco o de seis cuadros, entre ellas la que se presentó en 1991, en Edmund Peel y Asociados (21 de mayo, lotes 10,11 y 12 ; y 29 de octubre, lotes 12 y 13).

${ }^{13}$ El motivo del panal con la rosa aparece en la obra del taller del artista, de calidad discreta, que pasó por el comercio madrileño. Allí figura la dedicatoria al mecenas Nicolás Yñiguez, en la "Villa de Murillo de Gallego", que se encuentra cerca de la frontera de la provincia de Zaragoza, lo cual me llevó en 1995 a conjeturar que el pintor pudiera ser zaragozano: ver Jordan y Cherry 1995, p. 197, nota 24.

${ }_{14}$ Poleró describe así el cuadro: "Compuesto de una cesta de mimbres con melocotones, unos cuantos claveles, un plato con manzanas y ciruelas, y racimo de uvas colgando del techo, una codorniz muerta y un pito para la caza de estas aves. Toda aparece colocado sobre un tablero labrado de piedras." 


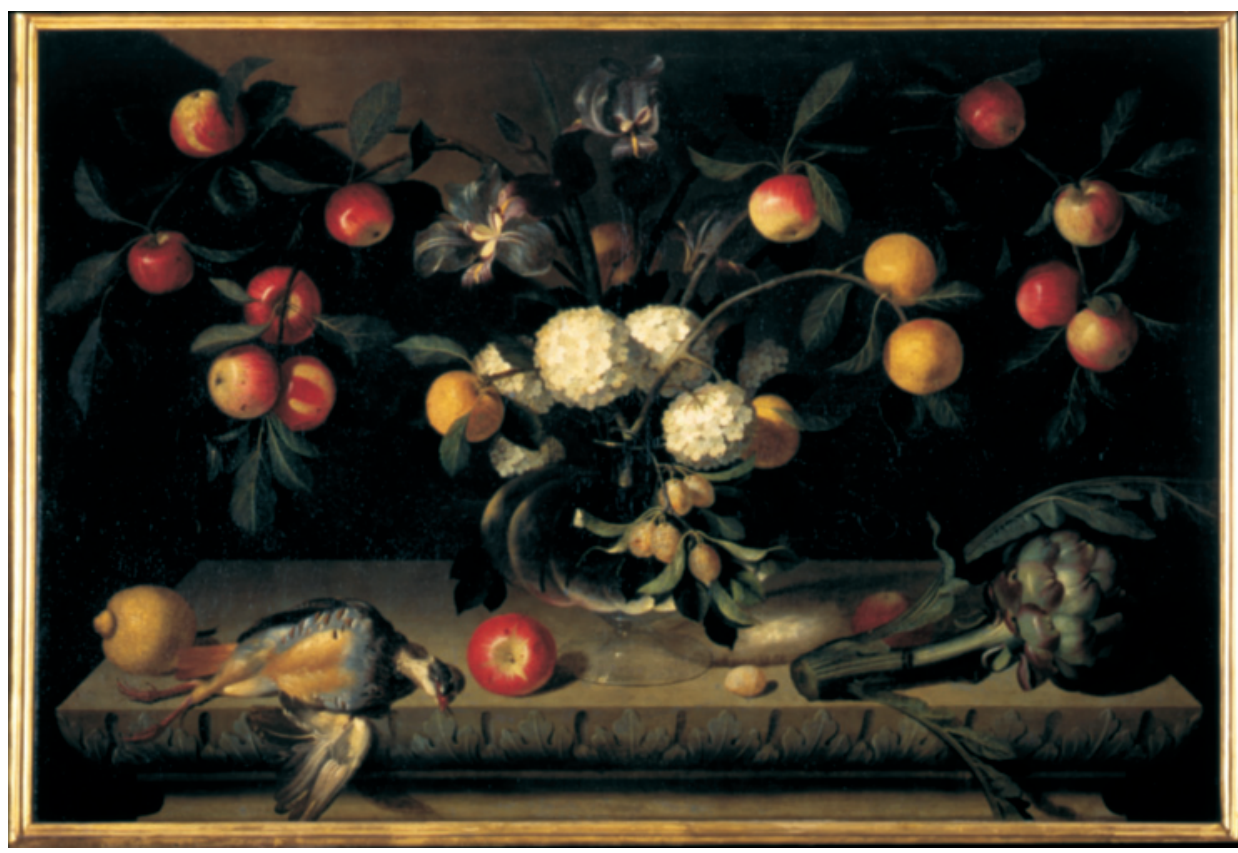

Fig. 6. Bernardo Polo, Alcachofa, codorniz y florero. Colección particular, Madrid.

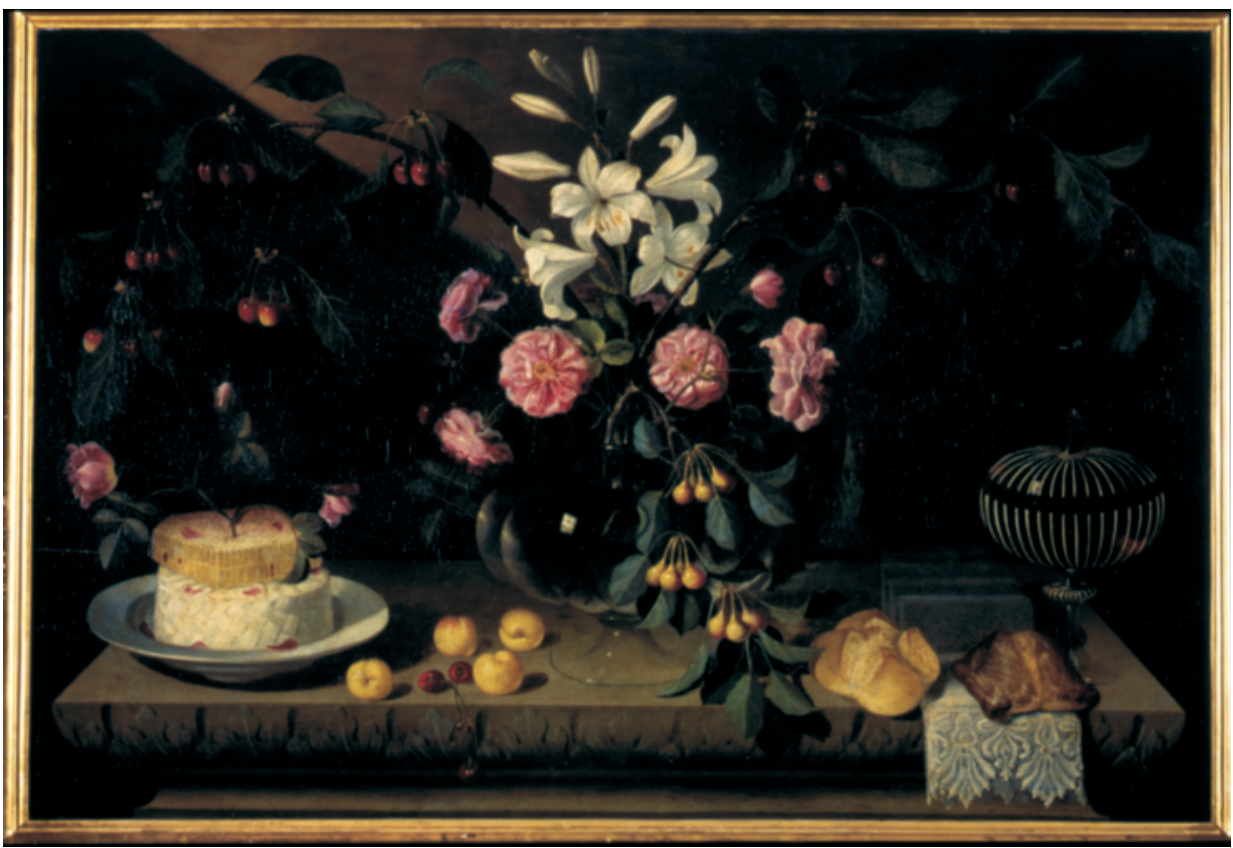

Fig. 7. Bernardo Polo, Panal, frutas y florero. Colección particular, Madrid. 


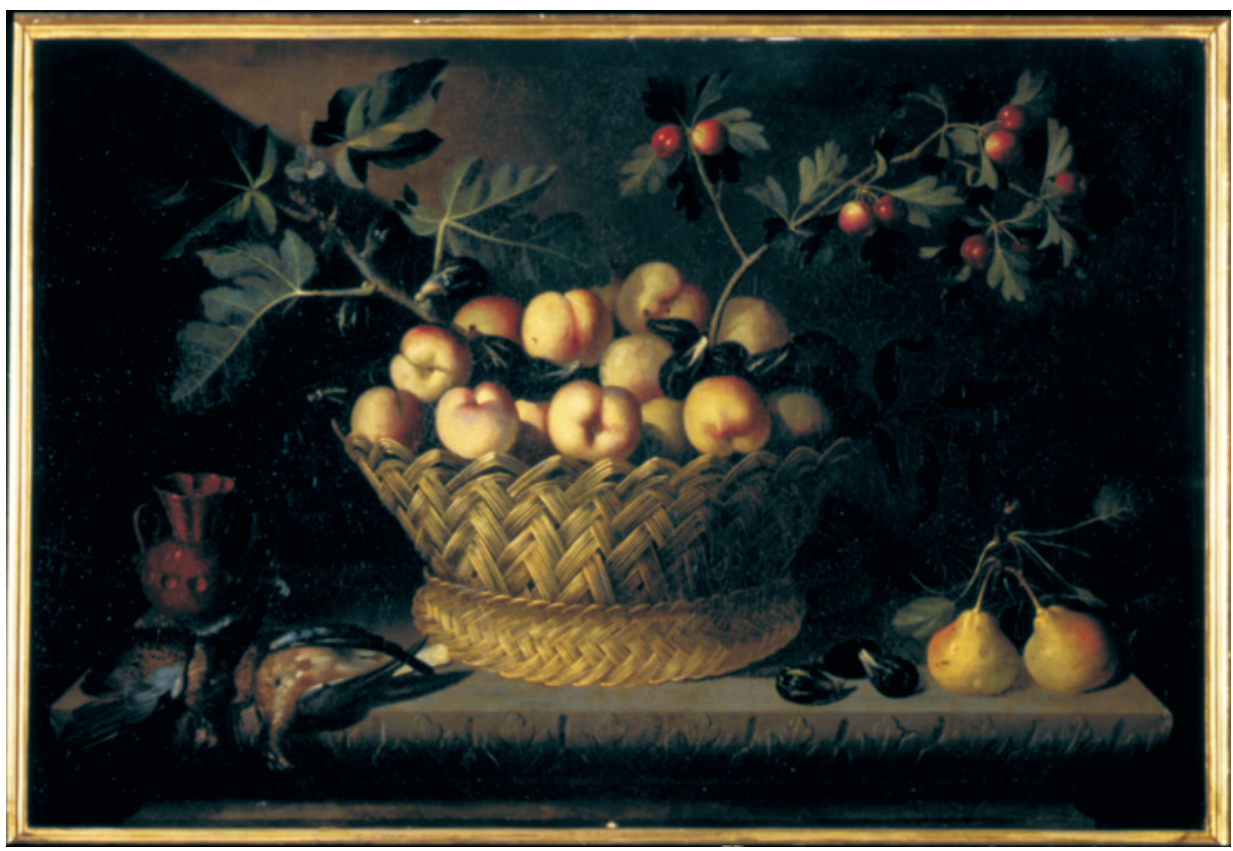

Fig. 8. Bernardo Polo, Canastilla de fruta, chochas y peras. Colección particular, Madrid.

Dentro de la serie, es evidente que las dos pinturas de bufetes rojos fueron concebidos como compañeros, ya que sus composiciones son complementarias, una de las mesas vista ligeramente de la izquierda, y la otra, de la derecha. En Arquimesa y bufete con frutas y florero (fig. 10) aparece el mismo melón que se ve en el cuadro firmado de Polo (fig. 2). Igualmente, otros elementos de la composición se repiten en diversas obras, por ejemplo el melón cortado sobre un plato colocado sobre el escritorio (o la arquimesa, como se le llamaba en Aragón), al fondo, en el centro ${ }^{15}$. Este escritorio incrustado de ébano y de marfil debió contribuir a la confusión que tuvo Poleró acerca de la autoría de los cuadros, ya que Hiepes también representó muebles similares en varias obras, y de hecho, en una ocasión colocó encima dos esferas decorativas de piedra jaspeada ${ }^{16}$. En Arquimesa y bufete con dulces, palomas y florero (fig. 9), la carcasa del escritorio es de una madera clara complementaria, también incrustada de ébano y de marfil, y el florero aparece en el lado opuesto de la composición. Los motivos de las palomas y de los dulces también se ven repetidos en otras obras de Polo o de su taller.

Bien si se vendían sueltas, en pareja, o en conjuntos mayores, claro está que los imponentes y atractivos bodegones de Bernardo Polo gozaban de éxito comercial en el último tercio del siglo XVII, y parece que el artista haya organizado su taller para responder con agilidad a las exigencias de su clientela en los encargos de esta decoración de alto nivel. El uso repetido de motivos y la reconfiguración de los elementos en combinaciones variadas recuerda la práctica que

15 Ver, por ejemplo, Naturaleza muerta con frutero, melón y cortina roja, en Jordan 1997, p. 123, cat. no. 14. Ver BRuÑÉn IBÁÑEZ, Ana I. et al.: Las artes en Zaragoza en el tercer cuarto del siglo XVII (1655-1675), Zaragoza, 1987, p. 352, para una explicación de lo que se llamaba "arquimesa" en Aragón, "escritorio" en Castilla, y de los "bufetes" vestidos de terciopelo.

16 Ver Pérez SÁnchez, Alfonso E.: Thomás Yepes, cat. exp., Madrid (Fundación Bancaja), 1995, p. 26, ill. 




Fig. 9. Bernardo Polo, Arquimesa y bufete con dulces, palomas y florero. Colección particular, Madrid.

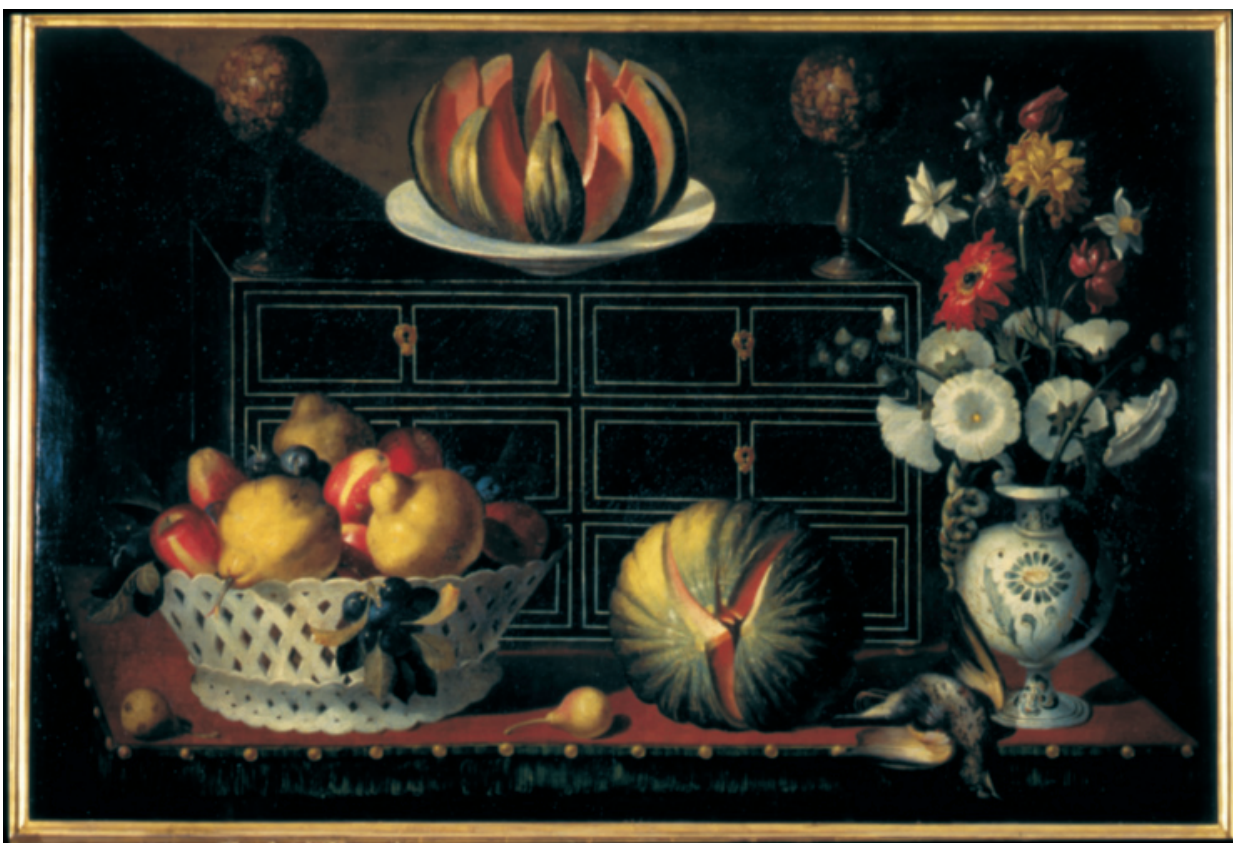

Fig. 10. Bernardo Polo, Arquimesa y bufete con frutas y florero. Colección particular, Madrid. 
ya había establecido medio siglo antes Juan Van der Hamen en su taller madrileño, y parece que el negocio de Polo fuera próspero. Pero, ¿quién es este tal Bernardo Polo? De él, ¿qué sabemos? Lamentablemente poco. Como ya hemos citado, mereció al menos mención tanto de Palomino como de Ceán Bermúdez, lo cual puede que sirva de pista en algún futuro para la investigación entre los archivos. Lo que sí sabemos es lo siguiente: en el apartado de El Parnaso español encabezada "Pintores célebres de la ciudad de Zaragoza", dice Palomino:

En la ínclita ciudad de Zaragoza ha habido otros pintores, que aunque su habilidad no ha sido general, la han tenido muy particular en algunas cosas: como en retratos Asensio, en flores Polo, en países Pertus, en batallas Rabiella, y en arquitectura, y ornatos Francisco Plano... Todos los cuales florecieron, y acabaron en el reinado del señor Carlos Segundo, y por los dichos nombres son allí conocidos ${ }^{17}$.

En una anotación en el margen, añade Palomino: "Murieron por los años de 1700". Ceán Bermúdez, que parece también conocer las obras de Polo, aporta poco más a las noticias de Palomino:

Polo (Bernardo) pintor y vecino de Zaragoza a fines del siglo XVII. Se distinguió en pintar flores y frutas por el natural: son muy estimados sus lienzos en aquella ciudad y en Madrid, donde se conservan en los gabinetes de los aficionados ${ }^{18}$.

La primera cita que nos llega de la actividad de Polo parece la del 2 de agosto de 1655, cuando se hace el inventario de la casa de Don Francisco Arguillur, canónigo del Pilar de Zaragoza, en el que se incluyen como "originales de Bernardo" cuatro naturalezas muertas de flores y frutas ${ }^{19}$. De 1668 nos llega la noticia de su enlace con Luisa Pérez de León, pero desconocemos si se trata de su primer matrimonio ${ }^{20}$. Finalmente, el Conde de la Viñaza hace esta reseña:

Polo (Bernabé), pintor. El capítulo de La Seo de Zaragoza le pagó, en los últimos años del siglo XVII, 285 libras por pintar lienzos, colores y galonear la bóveda de la capilla de San Pedro Arbués. Por el estilo deben ser también de su mano los adornos de la capilla del Sacramento y los de la de San Blas en la Catedral de Huesca ${ }^{21}$.

Esto implica que a Polo se le apreciaba por su elegancia, y que quizás desempeñara también el papel de decorador, hecho poco sorprendente en vista de sus decorativas naturalezas muertas, que, según Ceán, aun se comentaban en la lejanía de la Corte un siglo tras su muerte (“... se conservaban en los gabinetes de los aficionados"). En cambio, la existencia de una pintura grande que representa a Felipe $\mathrm{V}$ en alguna escena de la guerra de sucesión, si bien es del mismo autor, daría sustancia a la opinión de Palomino en cuanto a sus limitaciones como pintor (fig. 11). Firmado Bernardo Polo me fecit dat., el cuadro muestra los inconfundibles rasgos del joven monarca, en actitud ecuestre, y ostentando la francesa orden del Santo Espíritu ${ }^{22}$. La composición

17 Palomino, Antonio: El Parnaso español pintoresco laureado, Madrid, 1714, ed. 1947, p. 1087.

18 Cé́n Bermúdez, J. A.: Diccionario histórico de los mas ilustres profesores de las Bellas Artes en España, Madrid, 1800, vol. IV, p. 105.

19 BRUÑÉN IBÁÑEZ et al., op. cit., p. 255.

20 Ibid., p. 266.

${ }^{21}$ El Conde de la Viñaza, Adiciones al Diccionario histórico... de... Ceán Bermúdez, Madrid 1894, tomo III, p. 271.

${ }^{22}$ El cuadro apareció por primera vez en la subasta de pintura española de la sala Christie's en Londres, 29 de mayo de 1992, lote 327. Volvió a presentarse en subasta en Christie's Nueva York, 25 de noviembre de 1997, lote 345, pero esta vez con atribución a un pintor homónimo mejicano. No fue correctamente descrita la escena representada en ninguna de las dos ventas. 


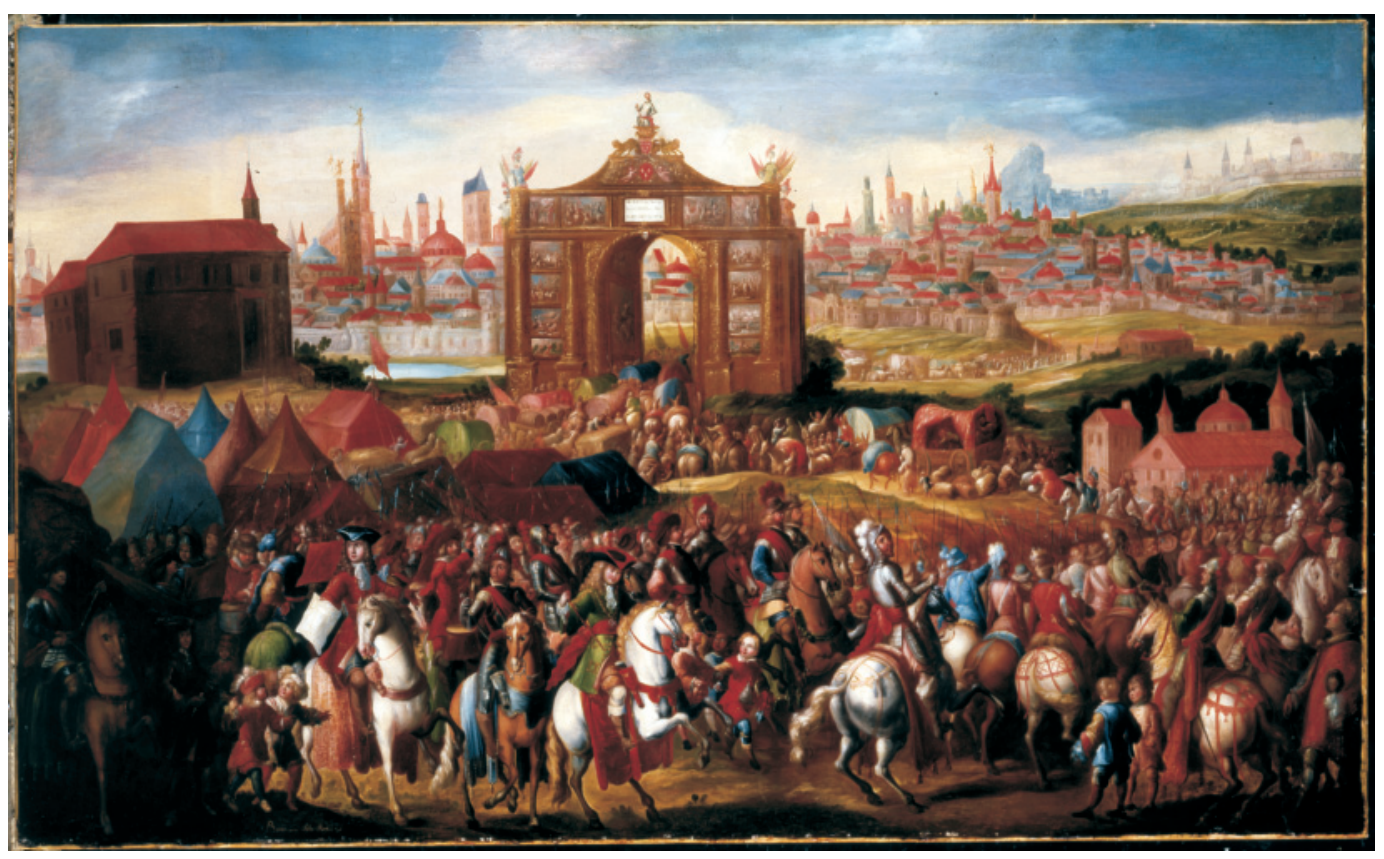

Fig. 11. Bernardo Polo, Felipe V triunfante. (C) 1997 Christie’s Images Limited.

está tomada de una estampa, publicada en 1681, que representa el socorro de París, que había sido cercado por Enrique IV en 1590, por parte de Alejandro Farnesio, suceso que tuvo lugar al final de otra terrible lucha de sucesión, afín a la que vivía España a comienzos de la época de los Borbones ${ }^{23}$. Al margen de la coincidencia que se produciría más tarde, con los desposorios de Felipe en 1714 con una descendida directa de Alejandro Farnesio, la representación aquí de Felipe V, ya rey, y en época de guerra, parece confirmar lo dicho por Palomino respecto a las fechas de Polo y de los artistas zaragozanos de su quinta: "murieron por los años de 1700."

WILLIAM B. JORDAN

${ }^{23}$ La ficha de catalogación de Christie's (ibid.) propone como fuente la estampa que ilustra Las Guerras de Flandes, de Fr. Famien Strada, de 1681. 